Original article

\title{
Design, synthesis and biological evaluation of novel arylpiperazine derivatives on human prostate cancer cell lines
}

\author{
Hong Chen ${ }^{a, b, 1}$, Fang Xu ${ }^{b, 1}$, Bing-Bing Xu ${ }^{b, 1}$, Jing-Yi Xu ${ }^{b}$, Bin-Hao Shao ${ }^{b}$, Bi-Yun Huang ${ }^{b}$, Mu Yuan ${ }^{b, *}$ \\ ${ }^{a}$ College of Chemistry and Chemical Engineering, Luoyang Normal University, Luoyang 471022, China \\ ${ }^{\mathrm{b}}$ Pharmaceutical Research Center, Guangzhou Medical University, Guangzhou 510182, China
}

\section{ARTICLE INFO}

Article history:

Received 7 April 2015

Received in revised form 9 June 2015

Accepted 15 June 2015

Available online

\section{Keywords:}

Synthesis

Arylpiperazine derivatives

Cytotoxic activity

CCK-8

Structure-activity relationship

\section{ABSTRACT}

A series of novel arylpiperazine derivatives was synthesized. The in vitro cytotoxic activities of all synthesized compounds against three human prostate cancer cell lines (PC-3, LNCaP, and DU145) were evaluated by a CCK-8 assay. Compounds 8, 10, 13, 17, and 20 exhibited strong cytotoxic activities against the tested cancer cell lines $\left(\mathrm{IC}_{50}<3 \mu \mathrm{mol} / \mathrm{L}\right)$. In addition, these compounds exhibited weak cytotoxic effects on human epithelial prostate normal cells WPMY-1. The structure-activity relationship (SAR) of these arylpiperazine derivatives was also discussed based on the obtained experimental data.

\section{Introduction}

Prostate cancer is the most common non-skin cancer in men and is the second-leading cause of cancer-related deaths in the US [1] Generally, the incidence rate of prostate cancer in Western countries is higher than that in Asian countries [2, 3]. Prostate cancer mortality typically results from metastasis to the bone and lymph nodes, as well as the progression from androgen-dependent to androgen-independent prostatic growth [4]. Although various chemotherapeutic agents are used solely or in combination with radiotherapy to treat advanced diseases, none of the conventional approaches to cancer therapy have been proven to be highly successful for prostate cancer [5]. Therefore, inventing and developing more effective, safe and selective anti-prostate cancer drugs are urgently needed. The selective targeting of tumor cells is the goal of modern cancer chemotherapy aimed at overcoming the nonspecific toxicity of most anticancer agents against normal cells [6]. At present, much of successful cancer chemotherapy probably lies in utilizing differences in cell kinetics between tumor and normal tissue, because most drugs can show some selective toxicity toward rapidly-dividing cells compared to noncycling cells [7]. So, drugs designed are expected to have high affinity with the novel targets, and they not only inhibit the proliferation but also differentiation of tumor cells and speed up their death [8].

Studies have shown that compounds with arylpiperazine moieties have anti-proliferative properties [9-11]. Naftopidil, an arylpiperazine ether derivative, is a spedic $\alpha_{1 \mathrm{~d}}$-adrenergic receptor antagonist $[12,13]$, and it is one of the most widely used $\alpha_{1}$ adrenergic receptor antagonists in Japan for the treatment of benign prostatic hyperplasia (BPH) [14, 15]. Recent studies have shown that naftopidil could possibly exert an anticancer effect and inhibit prostate cancer cell growth by arresting the G1 cell cycle phase [16, 17], as well as inducing apoptosis in malignant mesothelioma cell lines [18]. In our previous works [19, 20], we reported anti-prostate cancer activities of a series of arylpiperazine ether derivatives. In this work, we report the synthesis of a series of novel arylpiperazine amide derivatives (Scheme 1) with the intention of identifying much more effective anti-prostate cancer drugs. All synthesized compounds were evaluated for their cytotoxic activities against three human prostate cancer cell lines PC-3, LNCaP and DU145 cell line, and human prostate epithelial cell line WPMY-1. The SAR was further discussed on the basis of the obtained experimental data. As we expected, some arylpiperazine amide derivatives exhibited strong anti-prostate cancer activities against the tested cancer cells and potency superior to naftopidil.

\section{Experimental}

Reagents and solvents were commercially available. Solvents were dried and purified prior to use using standard procedures. Melting points were determined on SGW X-4 micro melting point apparatus (Shanghai Precision \& Scientific Instrument Co., Ltd, Shanghai, China) and are uncorrected. NMR spectra were determined on a Bruker AV-400 NB spectrometer (Faellanden, Switzerland) or Bruker AVANCE-500 spectrometer in $\mathrm{CDCl}_{3}$ or DMSO- $d_{6}$ using TMS as internal standard, and coupling constants $(J)$ are in $\mathrm{Hz}$. EI mass spectra were recorded on a DSQ mass spectrometer. ESI mass spectra were recorded on an Agilent 6460 Triple Quadrupole mass spectrometer (Agilent Technologies, USA). HRMS spectra were recorded on LTQ Orbitrap LC-MS (Thermo, Rockford, IL, USA).

\footnotetext{
${ }^{1}$ These authors contributed equally to this work.

* Corresponding author.

E-mail address: mryuanmu838@sina.com (M. Yuan).
} 
Elemental analyses $(\mathrm{C}, \mathrm{H}, \mathrm{N})$ were performed on an Elementar Vario EL elemental analyzer and the analytical results were within $\pm 0.4 \%$ of the theoretical values for the formula given unless otherwise listed. Flash column chromatography was performed with silica gel (Qing Dao Ocean Chemical Factory, 300-400 mesh) eluted with petroleum ether-ethyl acetate.

\subsection{Synthesis of 2-(4-(bromomethyl)phenyl)ethanol (2)}

To a cooled $\left(0{ }^{\circ} \mathrm{C}\right)$ solution of carboxylic acid $1(5.5 \mathrm{~g}, 24 \mathrm{mmol})$ in dry tetrahydrofuran (THF, $\left.100 \mathrm{~mL}\right)$ borane-dimethyl sulfide complex $\left(24 \mathrm{~mL}, 0.048 \mathrm{~mol}, 2 \mathrm{~mol} / \mathrm{L}\right.$ in THF) was added dropwise. The reaction mixture was stirred at $0{ }^{\circ} \mathrm{C}$ for $1 \mathrm{~h}$, and then at room temperature for $10 \mathrm{~h}$. Water $(20 \mathrm{~mL})$ was added slowly and extracted with ethyl acetate $(3 \times 100 \mathrm{~mL})$. The combined organic phase was successively washed with water and brine, dried over anhydrous magnesium sulfate, and concentrated in vacuo. The resulting residue was directly used without further purification in the following step.

\subsection{Synthesis of 2-(4-(2-hydroxyethyl)benzyl)isoindoline-1,3-dione (3)}

To a solution of compound $2(4.7 \mathrm{~g}, 22 \mathrm{mmol})$ in $\mathrm{CH}_{3} \mathrm{CN}(100 \mathrm{~mL})$, phthalimide potassium salt $(4.06 \mathrm{~g}, 22$ mmol $)$ and potassium carbonate $(18.2 \mathrm{~g}, 132 \mathrm{mmol})$ were added, and the reaction mixture was stirred at reflux for $16 \mathrm{~h}$. After cooling to ambient temperature, the reaction mixture was filtered through a Buchner funnel. After filtration the filtrate was concentrated in vacuo and the residue was purified by silica gel column chromatography using ethyl acetate/petroleum ether (1/8, v/v) as eluent to afford $4.72 \mathrm{~g}$ of compound 3 (70\% from compound 1) as a white solid. Mp 101-102 ${ }^{\circ} \mathrm{C}$; MS (EI, $\left.m / z\right): 281\left(\mathrm{M}^{+}\right), 236,251(100 \%), 232,204,192,178,160 ;{ }^{1} \mathrm{H}$ NMR (400 MHz, $\left.\mathrm{CDCl}_{3}\right): \delta 7.84(\mathrm{dd}, 2 \mathrm{H}, J=5.5,3.0 \mathrm{~Hz}), 7.70(\mathrm{dd}, 2 \mathrm{H}, J=5.5,3.0 \mathrm{~Hz}), 7.38(\mathrm{~d}, 2 \mathrm{H}, J=8.0 \mathrm{~Hz}), 7.17(\mathrm{~d}, 2 \mathrm{H}, J=8.0$ $\mathrm{Hz}), 4.82(\mathrm{~s}, 2 \mathrm{H}), 3.82(\mathrm{t}, 2 \mathrm{H}, J=6.5 \mathrm{~Hz}), 2.83(\mathrm{t}, 2 \mathrm{H}, J=6.5 \mathrm{~Hz}), 1.44(\mathrm{~s}, 1 \mathrm{H}) ;{ }^{13} \mathrm{C} \mathrm{NMR}\left(101 \mathrm{MHz}, \mathrm{CDCl}_{3}\right): \delta 168.5,138.6,135.0$, $134.4,132.6,129.7,129.3,123.7,64.0,41.7,39.3$.

\subsection{Synthesis of 2-(4-((1,3-dioxoisoindolin-2-yl)methyl)phenyl)ethyl 4-methylbenzenesulfonate (4)}

To a solution of compound $3(4.72 \mathrm{~g}, 16.8 \mathrm{mmol})$, triethylamine $(6.79 \mathrm{~g}, 67.2 \mathrm{mmol})$ and 4-dimethylaminopyridine $(0.13 \mathrm{~g}, 1.05$ mmol) in dry dichloromethane $\left(\mathrm{CH}_{2} \mathrm{Cl}_{2}, 80 \mathrm{~mL}\right)$ at $0{ }^{\circ} \mathrm{C}$ was added dropwise a solution of 4-toluene sulfonyl chloride (4.79 $\mathrm{g}, 25.2$ mmol) in $\mathrm{CH}_{2} \mathrm{Cl}_{2}(20 \mathrm{~mL})$. The reaction mixture was stirred at $0{ }^{\circ} \mathrm{C}$ for $16 \mathrm{~h}$. Water $(20 \mathrm{~mL})$ was added slowly and the reaction mixture was extracted with $\mathrm{CH}_{2} \mathrm{Cl}_{2}(2 \times 50 \mathrm{~mL})$. The combined organic phase was successively washed with water and brine, dried over anhydrous magnesium sulfate, and concentrated in vacuo. The residue was purified by silica gel column chromatography using ethyl acetate/petroleum ether $(1 / 10, \mathrm{v} / \mathrm{v})$ as eluent to afford $6.9 \mathrm{~g}(95 \%)$ of compound 4 as a white solid. Mp $108-109^{\circ} \mathrm{C}$; MS (EI, $\left.m / z\right)$ : 435 $\left(\mathrm{M}^{+}\right), 363,250$ (100\%), 235, 204, 178, 148; ${ }^{1} \mathrm{H}$ NMR (400 MHz, $\left.\mathrm{CDCl}_{3}\right): \delta 7.84(\mathrm{dd}, 2 \mathrm{H}, J=5.5,3.0 \mathrm{~Hz}), 7.71(\mathrm{dd}, 2 \mathrm{H}, J=5.5,3.0$ $\mathrm{Hz}), 7.66(\mathrm{~d}, 2 \mathrm{H}, J=8.3 \mathrm{~Hz}), 7.31(\mathrm{~d}, 2 \mathrm{H}, J=8.0 \mathrm{~Hz}), 7.28(\mathrm{~d}, 2 \mathrm{H}, J=8.3 \mathrm{~Hz}), 7.05(\mathrm{~d}, 2 \mathrm{H}, J=8.0 \mathrm{~Hz}), 4.81(\mathrm{~s}, 2 \mathrm{H}), 4.16(\mathrm{t}, 2 \mathrm{H}, J=$ $7.0 \mathrm{~Hz}), 2.91(\mathrm{t}, 2 \mathrm{H}, J=7.0 \mathrm{~Hz}), 2.42(\mathrm{~s}, 3 \mathrm{H}) ;{ }^{13} \mathrm{C} \mathrm{NMR}\left(101 \mathrm{MHz}, \mathrm{CDCl}_{3}\right): \delta 168.4,145.1,136.3,135.5,134.4,133.4,132.6,130.2$, $129.6,129.2,128.3,123.8,70.8,41.6,35.4,22.0$.

\subsection{Synthesis of 2-(4-(2-(4-phenylpiperazin-1-yl)ethyl)benzyl)isoindoline-1,3-dione (5)}

To a solution of $4(6.9 \mathrm{~g}, 15.9 \mathrm{mmol})$ in acetonitrile $\left(\mathrm{CH}_{3} \mathrm{CN}, 50 \mathrm{~mL}\right) \mathrm{N}$-phenylpiperazine $(3.09 \mathrm{~g}, 19.08 \mathrm{mmol})$ and potassium carbonate (13.16 g, $95.4 \mathrm{mmol}$ ) were added. The reaction mixture was stirred at reflux for $16 \mathrm{~h}$. After cooling to ambient temperature, the reaction mixture was filtered through a Buchner funnel. After filtration the filtrate was concentrated in vacuo and the residue was purified by silica gel column chromatography using ethyl acetate/petroleum ether $(1 / 8, \mathrm{v} / \mathrm{v})$ as eluent to afford $5.0 \mathrm{~g}$ (74\%) of compound 5 as a white solid. Mp $130-131{ }^{\circ} \mathrm{C}$; HRMS (ESI): calcd for $\mathrm{C}_{27} \mathrm{H}_{27} \mathrm{~N}_{3} \mathrm{O}_{2}, 426.2176$ [M+1] $]^{+}$, found, 426.2169 [M+1] $]^{+}$; ${ }^{1} \mathrm{H}$ NMR (400 MHz, $\left.\mathrm{CDCl}_{3}\right): \delta 7.84(\mathrm{dd}, 2 \mathrm{H}, J=5.5,3.0 \mathrm{~Hz}), 7.70(\mathrm{dd}, 2 \mathrm{H}, J=5.5,3.0 \mathrm{~Hz}), 7.37(\mathrm{~d}, 2 \mathrm{H}, J=8.1 \mathrm{~Hz}), 7.28-7.24(\mathrm{~m}, 2 \mathrm{H})$, $7.18(\mathrm{~d}, 2 \mathrm{H}, J=8.1 \mathrm{~Hz}), 6.93(\mathrm{~d}, 2 \mathrm{H}, J=7.9 \mathrm{~Hz}), 6.85(\mathrm{t}, 1 \mathrm{H}, J=7.3 \mathrm{~Hz}), 4.82(\mathrm{~s}, 2 \mathrm{H}), 3.22(\mathrm{t}, 4 \mathrm{H}, J=5.0 \mathrm{~Hz}), 2.81(\mathrm{dd}, 2 \mathrm{H}, J=9.8$, $6.3 \mathrm{~Hz}), 2.67(\mathrm{t}, 4 \mathrm{H}, J=5.0 \mathrm{~Hz}), 2.62(\mathrm{dd}, 2 \mathrm{H}, J=9.8,6.4 \mathrm{~Hz}) ;{ }^{13} \mathrm{C}$ NMR $\left(101 \mathrm{MHz}, \mathrm{CDCl}_{3}\right): \delta 168.1,151.4,140.0,134.3,134.0$, $132.3,129.2,129.1,128.9,123.4,119.8,116.2,60.4,53.3,49.3,41.4,33.3$.

\subsection{Synthesis of (4-(2-(4-phenylpiperazin-1-yl)ethyl)phenyl)methanamine (6)}

To a solution of $5(5.0 \mathrm{~g}, 11.8 \mathrm{mmol})$ in ethanol hydrazine hydrate $(5.9 \mathrm{~g}, 118 \mathrm{mmol})$ was added. The reaction mixture was stirred at room temperature for $16 \mathrm{~h}$. The reaction mixture was filtered through a Buchner funnel. After filtration the filtrate was concentrated in vacuo to afforded $3 \mathrm{~g}$ crude product $\mathbf{6}$. The resulting crude product was directly used without further purification in the following step.

\subsection{General procedure for the preparation of arylpiperazine derivative hydrochloride salts 7-20}

To a solution of $6(100 \mathrm{mg}, 3.39 \mathrm{mmol})$ in $\mathrm{CH}_{2} \mathrm{Cl}_{2}(20 \mathrm{~mL})$ was added the corresponding acid (1.2 equiv.), $N, N-$ diisopropylethylamine (DIPEA, 4 equiv.) and 2-(7-aza-1H-benzotriazole-1-yl)-1,1,3,3-tetramethyluroniumhexafluorophosphate (HATU, 1 equiv.). The reaction mixture was stirred at room temperature for $16 \mathrm{~h}$. The reaction mixture was filtered through a Buchner funnel. After filtration the filtrate was concentrated in vacuo and the residue was purified by silica gel column chromatography using ethyl acetate/petroleum ether (1/7, v/v) as eluent to afford the corresponding products (7-20). To a solution of the above corresponding products in ethyl acetate was added dropwise $4 \mathrm{~mol} / \mathrm{L} \mathrm{HCl}$ solution in ethyl acetate $(50 \mathrm{~mL})$, while maintaining stirring for $0.5 \mathrm{~h}$. Then the resulting solid was collected by filtration to give corresponding hydrochloride salts as a white solid. 
$\mathrm{N}$-(4-(2-(4-Phenylpiperazin-1-yl)ethyl)benzyl)benzamide dihydrochloride (7): White solid; Yield: 45\%; $\mathrm{Mp} 152-153{ }^{\circ} \mathrm{C}(\mathrm{HCl}$ salt); MS (ESI, $m / z): 400.2[\mathrm{M}+1]^{+} ;{ }^{1} \mathrm{H}$ NMR (400 MHz, DMSO- $\left.d_{6}\right): \delta 11.51(\mathrm{~s}, 1 \mathrm{H}), 8.68(\mathrm{t}, 1 \mathrm{H}, J=6.0 \mathrm{~Hz}), 7.68-7.54(\mathrm{~m}, 2 \mathrm{H}), 7.35-7.20$ $(\mathrm{m}, 7 \mathrm{H}), 7.14(\mathrm{~d}, 1 \mathrm{H}, J=8.3 \mathrm{~Hz}), 7.05(\mathrm{t}, 3 \mathrm{H}, J=7.6 \mathrm{~Hz}), 6.77(\mathrm{t}, 1 \mathrm{H}, J=7.3 \mathrm{~Hz}), 4.46(\mathrm{~d}, 2 \mathrm{H}, J=6.0 \mathrm{~Hz}), 3.81(\mathrm{~d}, 2 \mathrm{H}, J=11.0 \mathrm{~Hz})$, $3.64(\mathrm{~d}, 2 \mathrm{H}, J=11.0 \mathrm{~Hz}), 3.41-3.02(\mathrm{~m}, 8 \mathrm{H})$; Anal. Calcd. for $\mathrm{C}_{26} \mathrm{H}_{29} \mathrm{~N}_{3} \mathrm{O} .2 \mathrm{HCl}$ : C, 66.10; H, 6.61; N, 8.89. Found: C, 66.25; H, 6.67; $\mathrm{N}, 8.78$.

$N$-(4-(2-(4-Phenylpiperazin-1-yl)ethyl)benzyl)-2-methoxybenzamide hydrochloride dihydrochloride (8): White solid; Yield: 52\%; Mp 168-169 ${ }^{\circ} \mathrm{C}(\mathrm{HCl} \mathrm{salt})$; MS (ESI, $\left.m / z\right): 430.2[\mathrm{M}+1]^{+} ;{ }^{1} \mathrm{H}$ NMR $\left(400 \mathrm{MHz}, \mathrm{DMSO}-d_{6}\right): \delta 11.58(\mathrm{~s}, 1 \mathrm{H}), 8.66(\mathrm{t}, 1 \mathrm{H}, J=6.0 \mathrm{~Hz})$, $7.74(\mathrm{dd}, 1 \mathrm{H}, J=7.6,1.7 \mathrm{~Hz}), 7.52-7.41(\mathrm{~m}, 1 \mathrm{H}), 7.35-7.20(\mathrm{~m}, 6 \mathrm{H}), 7.14(\mathrm{~d}, 1 \mathrm{H}, J=8.3 \mathrm{~Hz}), 7.03(\mathrm{t}, 3 \mathrm{H}, J=7.6 \mathrm{~Hz}), 6.87(\mathrm{t}, 1 \mathrm{H}, J=$ $7.3 \mathrm{~Hz}), 4.48(\mathrm{~d}, 2 \mathrm{H}, J=6.0 \mathrm{~Hz}), 3.89(\mathrm{~s}, 3 \mathrm{H}), 3.82(\mathrm{~d}, 2 \mathrm{H}, J=11.0 \mathrm{~Hz}), 3.62(\mathrm{~d}, 2 \mathrm{H}, J=11.0 \mathrm{~Hz}), 3.41-3.02(\mathrm{~m}, 8 \mathrm{H}) ;{ }^{13} \mathrm{C} \mathrm{NMR}(101$ MHz, DMSO- $\left.d_{6}\right): \delta 165.3,157.1,149.6,138.4,135.6,132.3,130.5,129.3,128.7,127.5,123.4,120.6,120.2,116.2,112.2,56.2,56.0$, 50.6, 45.6, 42.4, 40.3, 29.0; Anal. Calcd. for $\mathrm{C}_{27} \mathrm{H}_{31} \mathrm{~N}_{3} \mathrm{O}_{2} .2 \mathrm{HCl}$ : C, 64.54; H, 6.62; N, 8.36. Found: C, 64.12; H, 6.67; N, 8.19.

$\mathrm{N}$-(4-(2-(4-Phenylpiperazin-1-yl)ethyl)benzyl)-2-fluorobenzamide dihydrochloride (9): White solid; Yield: $46 \%$; $\mathrm{Mp} 177-178{ }^{\circ} \mathrm{C}$ (HCl salt); MS (ESI, $m / z): 418.2[\mathrm{M}+1]^{+} ;{ }^{1} \mathrm{H}$ NMR (400 MHz, DMSO- $\left.d_{6}\right): \delta 11.54(\mathrm{~s}, 1 \mathrm{H}), 8.86(\mathrm{t}, 1 \mathrm{H}, J=6.0 \mathrm{~Hz}), 7.64(\mathrm{td}, 1 \mathrm{H}, J=$ $7.5,1.5 \mathrm{~Hz}), 7.57-7.48(\mathrm{~m}, 1 \mathrm{H}), 7.32-7.25(\mathrm{~m}, 8 \mathrm{H}), 7.02(\mathrm{~d}, 2 \mathrm{H}, J=8.0 \mathrm{~Hz}), 6.87(\mathrm{t}, 1 \mathrm{H}, J=7.3 \mathrm{~Hz}), 4.45(\mathrm{~d}, 2 \mathrm{H}, J=6.0 \mathrm{~Hz}), 3.82(\mathrm{~d}$, $2 \mathrm{H}, J=11.0 \mathrm{~Hz}), 3.62(\mathrm{~d}, 2 \mathrm{H}, J=11.0 \mathrm{~Hz}), 3.41-3.06(\mathrm{~m}, 8 \mathrm{H}) ;{ }^{13} \mathrm{C}$ NMR $\left(101 \mathrm{MHz}, \mathrm{DMSO}-d_{6}\right): \delta 163.9,160.5,158.0,149.6,138.0$, $135.7,132.5,132.5,130.2,129.3,128.7,127.6,124.6,124.3,124.1,120.2,116.3,116.2,56.2,50.7,45.6$, 42.5, 29.0; Anal. Calcd. for $\mathrm{C}_{26} \mathrm{H}_{28} \mathrm{FN}_{3} \mathrm{O} .2 \mathrm{HCl}: \mathrm{C}, 63.67 ; \mathrm{H}, 6.17 ; \mathrm{N}, 8.57$. Found: C, 63.36; H, 6.41; N, 8.23.

$N$-(4-(2-(4-Phenylpiperazin-1-yl)ethyl)benzyl)cyclohexanecarboxamide dihydrochloride (10): White solid; Yield: 40\%; Mp 192-193 ${ }^{\circ} \mathrm{C}(\mathrm{HCl} \mathrm{salt}) ; \mathrm{MS}(\mathrm{ESI}, \mathrm{m} / \mathrm{z}): 406.2[\mathrm{M}+1]^{+} ;{ }^{1} \mathrm{H}$ NMR (400 MHz, DMSO- $\left.d_{6}\right): \delta 11.36(\mathrm{~s}, 1 \mathrm{H}), 8.21(\mathrm{t}, 1 \mathrm{H}, J=6.0 \mathrm{~Hz}), 7.31-7.16(\mathrm{~m}$, $7 \mathrm{H}), 7.02(\mathrm{~d}, 2 \mathrm{H}, J=8.0 \mathrm{~Hz}), 6.87(\mathrm{t}, 1 \mathrm{H}, J=7.2 \mathrm{~Hz}), 4.22(\mathrm{~d}, 2 \mathrm{H}, J=6.0 \mathrm{~Hz}), 3.82(\mathrm{~d}, 2 \mathrm{H}, J=10.6 \mathrm{~Hz}), 3.62(\mathrm{~d}, 2 \mathrm{H}, J=10.6 \mathrm{~Hz})$, $3.41-3.02(\mathrm{~m}, 8 \mathrm{H}), 2.24-2.07(\mathrm{~m}, 1 \mathrm{H}), 1.70(\mathrm{~d}, 4 \mathrm{H}, J=11.2 \mathrm{~Hz}), 1.61(\mathrm{~d}, 1 \mathrm{H}, J=10.1 \mathrm{~Hz}), 1.46-1.08(\mathrm{~m}, 6 \mathrm{H}) ;{ }^{13} \mathrm{C} \mathrm{NMR}(101 \mathrm{MHz}$, DMSO- $\left.d_{6}\right): \delta 175.2,149.6,138.6,135.5,129.2,128.7,127.4,120.2,116.1,56.2,50.7,45.6,44.1,41.62,29.4,29.0,25.6,25.4 ;$ Anal. Calcd. for $\mathrm{C}_{26} \mathrm{H}_{33} \mathrm{~N}_{3} \mathrm{O} .2 \mathrm{HCl}$ : C, 65.26; H, 7.79; N, 8.78. Found: C, 64.91; H, 7.60; N, 8.50.

$N$-(4-(2-(4-Phenylpiperazin-1-yl)ethyl)benzyl)cyclopentanecarboxamide dihydrochloride (11): White solid; Yield: 44\%; Mp 161$162{ }^{\circ} \mathrm{C}$ ( $\mathrm{HCl}$ salt); MS (ESI, $\left.m / z\right): 392.2[\mathrm{M}+1]^{+} ;{ }^{1} \mathrm{H}$ NMR (400 MHz, DMSO- $\left.d_{6}\right): \delta 11.54(\mathrm{~s}, 1 \mathrm{H}), 8.28(\mathrm{t}, 1 \mathrm{H}, J=6.0 \mathrm{~Hz}), 7.37-7.16$ $(\mathrm{m}, 6 \mathrm{H}), 7.02(\mathrm{~d}, 2 \mathrm{H}, J=8.0 \mathrm{~Hz}), 6.87(\mathrm{t}, 1 \mathrm{H}, J=7.2 \mathrm{~Hz}), 4.23(\mathrm{~d}, 2 \mathrm{H}, J=6.0 \mathrm{~Hz}), 3.82(\mathrm{~d}, 2 \mathrm{H}, J=10.6 \mathrm{~Hz}), 3.62(\mathrm{~d}, 2 \mathrm{H}, J=10.6 \mathrm{~Hz})$, $3.42-3.00(\mathrm{~m}, 8 \mathrm{H}), 2.78-2.54(\mathrm{~m}, 1 \mathrm{H}), 1.78-1.50(\mathrm{~m}, 8 \mathrm{H}) ;{ }^{13} \mathrm{C}$ NMR $\left(101 \mathrm{MHz}, \mathrm{DMSO}-d_{6}\right): \delta 175.1,149.4,138.4,135.3,129.0,128.5$, $127.3,120.0,115.9,56.0,50.4,45.3,44.2,41.6,29.9,28.8,25.5$; Anal. Calcd. for $\mathrm{C}_{25} \mathrm{H}_{33} \mathrm{~N}_{3} \mathrm{O} .2 \mathrm{HCl}$ : C, 64.65; H, 7.60; N, 9.05. Found: C, $64.58 ; \mathrm{H}, 7.74 ; \mathrm{N}, 8.85$.

N-(4-(2-(4-Phenylpiperazin-1-yl)ethyl)benzyl)cyclopropanecarboxamide dihydrochloride (12): White solid; Yield: 39\%; Mp 172$173{ }^{\circ} \mathrm{C}(\mathrm{HCl} \mathrm{salt}) ; \mathrm{MS}(\mathrm{ESI}, \mathrm{m} / \mathrm{z}): 364.2[\mathrm{M}+1]^{+} ;{ }^{1} \mathrm{H}$ NMR $\left(500 \mathrm{MHz}, \mathrm{DMSO}-d_{6}\right): \delta 11.03(\mathrm{~s}, 1 \mathrm{H}), 8.58(\mathrm{t}, 1 \mathrm{H}, J=6.0 \mathrm{~Hz}), 7.36-7.15$ $(\mathrm{m}, 6 \mathrm{H}), 7.02(\mathrm{~d}, 2 \mathrm{H}, J=8.0 \mathrm{~Hz}), 6.87(\mathrm{t}, 1 \mathrm{H}, J=7.2 \mathrm{~Hz}), 4.25(\mathrm{~d}, 2 \mathrm{H}, J=6.0 \mathrm{~Hz}), 3.84(\mathrm{~d}, 2 \mathrm{H}, J=10.6 \mathrm{~Hz}), 3.63(\mathrm{~d}, 2 \mathrm{H}, J=10.6 \mathrm{~Hz})$, $3.44-2.98(\mathrm{~m}, 8 \mathrm{H}), 1.72-1.35(\mathrm{~m}, 1 \mathrm{H}), 0.78-0.54(\mathrm{~m}, 4 \mathrm{H}) ;{ }^{13} \mathrm{C}$ NMR $\left(126 \mathrm{MHz}, \mathrm{DMSO}-d_{6}\right): \delta 172.8,149.8,138.6,135.7,129.4,128.9$, 127.9, 120.3, 116.2, 56.3, 50.8, 45.7, 42.1, 29.2, 13.8, 6.5; Anal. Calcd. for $\mathrm{C}_{23} \mathrm{H}_{29} \mathrm{~N}_{3} \mathrm{O} .2 \mathrm{HCl}$ : C, 63.30; H, 7.16; N, 9.63. Found: C, $62.97 ; \mathrm{H}, 6.39 ; \mathrm{N}, 9.57$.

$\mathrm{N}$-(4-(2-(4-Phenylpiperazin-1-yl)ethyl)benzyl)-1-naphthamide dihydrochloride (13): White solid; Yield: $59 \%$; $\mathrm{Mp} 191-192{ }^{\circ} \mathrm{C}(\mathrm{HCl}$ salt); MS (ESI, m/z): $450.2[\mathrm{M}+1]^{+} ;{ }^{1} \mathrm{H}$ NMR $\left(400 \mathrm{MHz}, \mathrm{DMSO}-d_{6}\right) \delta$ in ppm: $11.56(\mathrm{~s}, 1 \mathrm{H}), 9.09(\mathrm{t}, 1 \mathrm{H}, J=6.0 \mathrm{~Hz}), 8.23-8.18(\mathrm{~m}$, $1 \mathrm{H}), 8.02(\mathrm{~d}, 1 \mathrm{H}, J=8.2 \mathrm{~Hz}), 8.00-7.96(\mathrm{~m}, 1 \mathrm{H}), 7.65(\mathrm{~d}, 1 \mathrm{H}, J=6.5 \mathrm{~Hz}), 7.59-7.51(\mathrm{~m}, 3 \mathrm{H}), 7.39(\mathrm{~d}, 2 \mathrm{H}, J=8.0 \mathrm{~Hz}), 7.32-7.21(\mathrm{~m}$, $4 \mathrm{H}), 7.02(\mathrm{~d}, 2 \mathrm{H}, J=8.0 \mathrm{~Hz}), 6.87(\mathrm{t}, 1 \mathrm{H}, J=7.2 \mathrm{~Hz}), 4.53(\mathrm{~d}, 2 \mathrm{H}, J=6.0 \mathrm{~Hz}), 3.82(\mathrm{~d}, 2 \mathrm{H}, J=10.9 \mathrm{~Hz}), 3.63(\mathrm{~d}, 2 \mathrm{H}, J=10.9 \mathrm{~Hz})$, 3.51-3.01 (m, 8H); ${ }^{13} \mathrm{C}$ NMR (101 MHz, DMSO- $\left.d_{6}\right) \delta$ in ppm: 169.3, 150.2, 138.9, 136.3, 135.3, 133.9, 130.6, 129.9, 129.4, 129.0, 128.3, 127.4, 126.9, 126.0, 125.9, 125.7, 120.8, 116.8, 56.8, 51.3, 46.2, 43.0, 29.6; Anal. Calcd for $\mathrm{C}_{30} \mathrm{H}_{31} \mathrm{~N}_{3} \mathrm{O} .2 \mathrm{HCl}: \mathrm{C}, 68.96$; $\mathrm{H}, 6.37$; N, 8.04. Found: C, 68.59; H, 6.42; N, 7.89.

$\mathrm{N}$-(4-(2-(4-Phenylpiperazin-1-yl)ethyl)benzyl)-2-naphthamide dihydrochloride (14): White solid; Yield: $37 \%$; $\mathrm{Mp} 188-189{ }^{\circ} \mathrm{C}(\mathrm{HCl}$ salt); MS (ESI, $m / z): 450.2[\mathrm{M}+1]^{+} ;{ }^{1} \mathrm{H}$ NMR (400 MHz, DMSO- $\left.d_{6}\right): \delta 11.42(\mathrm{~s}, 1 \mathrm{H}), 9.24(\mathrm{t}, 1 \mathrm{H}, J=6.0 \mathrm{~Hz}), 8.52(\mathrm{~s}, 1 \mathrm{H}), 8.13-7.88$ $(\mathrm{m}, 4 \mathrm{H}), 7.72-7.50(\mathrm{~m}, 2 \mathrm{H}), 7.35(\mathrm{~d}, 2 \mathrm{H}, J=8.0 \mathrm{~Hz}), 7.30-7.09(\mathrm{~m}, 4 \mathrm{H}), 7.01(\mathrm{~d}, 2 \mathrm{H}, J=8.0 \mathrm{~Hz}), 6.86(\mathrm{t}, 1 \mathrm{H}, J=7.2 \mathrm{~Hz}), 4.52(\mathrm{~d}, 2 \mathrm{H}$, $J=6.0 \mathrm{~Hz}), 3.82(\mathrm{~d}, 2 \mathrm{H}, J=10.9 \mathrm{~Hz}), 3.62(\mathrm{~d}, 2 \mathrm{H}, J=10.9 \mathrm{~Hz}), 3.48-2.93(\mathrm{~m}, 8 \mathrm{H}) ;{ }^{13} \mathrm{C}$ NMR $\left(101 \mathrm{MHz}, \mathrm{DMSO}-d_{6}\right): \delta 165.9,149.2$, 138.0, 135.2, 133.8, 131.9, 131.4, 128.8, 128.5, 128.3, 127.6, 127.4, 127.3, 127.2, 126.4, 123.9, 119.7, 115.7, 55.8, 50.3, 45.1, 42.2, 28.6; Anal. Calcd. for $\mathrm{C}_{30} \mathrm{H}_{31} \mathrm{~N}_{3} \mathrm{O} .2 \mathrm{HCl}$ : C, 68.96; H, 6.37; N, 8.04. Found: C, 68.62; H, 6.43; N, 7.93.

$\mathrm{N}$-(4-(2-(4-Phenylpiperazin-1-yl)ethyl)benzyl)-4-fluoro-1-naphthamide dihydrochloride (15): White solid; Yield: 50\%; Mp 202-203 ${ }^{\circ} \mathrm{C}$ ( $\mathrm{HCl}$ salt); MS (ESI, $\left.m / z\right): 468.1[\mathrm{M}+1]^{+} ;{ }^{1} \mathrm{H}$ NMR (400 MHz, DMSO- $\left.d_{6}\right): \delta 11.45(\mathrm{~s}, 1 \mathrm{H}), 9.11(\mathrm{t}, 1 \mathrm{H}, J=6.0 \mathrm{~Hz}), 8.39-8.20(\mathrm{~m}$, $1 \mathrm{H}), 8.11(\mathrm{dd}, 1 \mathrm{H}, J=6.4,3.2 \mathrm{~Hz}), 7.76-7.58(\mathrm{~m}, 3 \mathrm{H}), 7.48-7.15(\mathrm{~m}, 7 \mathrm{H}), 7.02(\mathrm{~d}, 2 \mathrm{H}, J=8.0 \mathrm{~Hz}), 6.87(\mathrm{t}, 1 \mathrm{H}, J=7.2 \mathrm{~Hz}), 4.52(\mathrm{~d}$, $2 \mathrm{H}, J=6.0 \mathrm{~Hz}), 3.82(\mathrm{~d}, 2 \mathrm{H}, J=10.9 \mathrm{~Hz}), 3.63(\mathrm{~d}, 2 \mathrm{H}, J=10.9 \mathrm{~Hz}), 3.46-3.00(\mathrm{~m}, 8 \mathrm{H}) ;{ }^{13} \mathrm{C} \mathrm{NMR}\left(101 \mathrm{MHz}, \mathrm{DMSO}-d_{6}\right): \delta 167.9$, $160.0,157.5,149.7,138.2,135.7,131.7,131.1,129.2,128.8,128.0,127.7,127.1,126.1,126.0,125.7,123.1,122.9,120.1,116.1$, 109.0, 108.8, 56.2, 50.7, 45.5, 42.5, 29.0; Anal. Calcd. for $\mathrm{C}_{30} \mathrm{H}_{30} \mathrm{~N}_{4} \mathrm{O} .2 \mathrm{HCl}$ : C, 66.66; H, 5.97; N, 7.77. Found: C, 66.40; H, 6.23; N, 7.53 .

$N$-(4-(2-(4-Phenylpiperazin-1-yl)ethyl)benzyl)-1H-indole-2-carboxamide dihydrochloride ( 16 ): White solid; Yield: 57\%; Mp 163$164{ }^{\circ} \mathrm{C}(\mathrm{HCl}$ salt); MS (ESI, $m / z): 439.1[\mathrm{M}+1]^{+} ;{ }^{1} \mathrm{H}$ NMR $\left(400 \mathrm{MHz}, \mathrm{DMSO}-d_{6}\right): \delta 11.63(\mathrm{~s}, 1 \mathrm{H}), 11.47(\mathrm{~s}, 1 \mathrm{H}), 9.11(\mathrm{t}, 1 \mathrm{H}, J=6.0$ $\mathrm{Hz}), 7.60(\mathrm{~d}, 1 \mathrm{H}, J=8.0 \mathrm{~Hz}), 7.43(\mathrm{~d}, 1 \mathrm{H}, J=8.0 \mathrm{~Hz}), 7.33(\mathrm{~d}, 2 \mathrm{H}, J=8.0 \mathrm{~Hz}), 7.30-6.97$ (m, 9H), $6.87(\mathrm{t}, 1 \mathrm{H}, J=7.2 \mathrm{~Hz}), 4.49(\mathrm{~d}$, 
$2 \mathrm{H}, J=6.0 \mathrm{~Hz}), 3.81(\mathrm{~d}, 2 \mathrm{H}, J=10.8 \mathrm{~Hz}), 3.61(\mathrm{~d}, 2 \mathrm{H}, J=10.8 \mathrm{~Hz}), 3.36-3.02(\mathrm{~m}, 8 \mathrm{H}) ;{ }^{13} \mathrm{C} \mathrm{NMR}\left(101 \mathrm{MHz}, \mathrm{DMSO}-d_{6}\right): \delta 161.2$, 149.6, 138.4, 136.6, 135.7, 131.8, 129.2, 128.7, 127.7, 127.2, 123.4, 121.6, 120.2, 119.8, 116.2, 112.4, 102.9, 56.2, 50.7, 45.6, 42.0, 29.0; Anal. Calcd. for $\mathrm{C}_{28} \mathrm{H}_{30} \mathrm{~N}_{4} \mathrm{O} .2 \mathrm{HCl}$ : C, 65.75; H, 6.31; N, 10.95. Found: C, 65.59; H, 6.45; N, 10.69.

N-(4-(2-(4-Phenylpiperazin-1-yl)ethyl)benzyl)-5-fluoro-1H-indole-2-carboxamid dihydrochloride (17): White solid; Yield: 47\%; Mp $193-194{ }^{\circ} \mathrm{C}(\mathrm{HCl}$ salt); MS (ESI, $m / z): 457.1[\mathrm{M}+1]^{+} ;{ }^{1} \mathrm{H}$ NMR $\left(500 \mathrm{MHz}, \mathrm{DMSO}-d_{6}\right): \delta 11.75(\mathrm{~s}, 1 \mathrm{H}), 11.17(\mathrm{~s}, 1 \mathrm{H}), 9.16(\mathrm{t}, 1 \mathrm{H}, J=$ $6.0 \mathrm{~Hz}), 7.50-7.21(\mathrm{~m}, 9 \mathrm{H}), 7.07-6.94(\mathrm{~m}, 3 \mathrm{H}), 6.86(\mathrm{t}, 1 \mathrm{H}, J=7.2 \mathrm{~Hz}), 4.48(\mathrm{~d}, 2 \mathrm{H}, J=6.0 \mathrm{~Hz}), 3.81(\mathrm{~d}, 2 \mathrm{H}, J=10.8 \mathrm{~Hz}), 3.61(\mathrm{~d}$, $2 \mathrm{H}, J=10.8 \mathrm{~Hz}), 3.34-3.04(\mathrm{~m}, 8 \mathrm{H}) ;{ }^{13} \mathrm{C}$ NMR $(126 \mathrm{MHz}$, DMSO-d $)$ : $\delta 160.9,158.2,156.3,149.7,138.3,135.7,133.4,133.3,129.3$, 128.8, 127.7, 127.3, 127.2, 120.2, 116.1, 113.7, 113.6, 112.3, 112.0, 105.9, 105.7, 102.9, 56.3, 50.7, 45.6, 42.0, 29.1; Anal. Calcd. for $\mathrm{C}_{28} \mathrm{H}_{29} \mathrm{FN}_{4} \mathrm{O} .2 \mathrm{HCl}: \mathrm{C}, 63.52 ; \mathrm{H}, 5.90 ; \mathrm{N}, 10.58$. Found: C, 63.87; H, 5.99; N, 10.47.

$\mathrm{N}$-(4-(2-(4-Phenylpiperazin-1-yl)ethyl)benzyl)benzofuran-2-carboxamide (18): White solid; Yield: 56\%; Mp 166-167 ${ }^{\circ} \mathrm{C}$; MS (ESI, $m / z): 440.1[\mathrm{M}+1]^{+} ;{ }^{1} \mathrm{H}$ NMR $\left(400 \mathrm{MHz}, \mathrm{DMSO}-d_{6}\right): \delta 9.21(\mathrm{t}, 1 \mathrm{H}, J=6.0 \mathrm{~Hz}), 7.77(\mathrm{~d}, 1 \mathrm{H}, J=7.8 \mathrm{~Hz}), 7.65(\mathrm{~d}, 1 \mathrm{H}, J=8.3 \mathrm{~Hz}), 7.56$ $(\mathrm{s}, 1 \mathrm{H}), 7.46(\mathrm{t}, 1 \mathrm{H}, J=7.8 \mathrm{~Hz}), 7.33(\mathrm{t}, 1 \mathrm{H}, J=7.5 \mathrm{~Hz}), 7.26-7.17(\mathrm{~m}, 6 \mathrm{H}), 6.91(\mathrm{~d}, 2 \mathrm{H}, J=8.0 \mathrm{~Hz}), 6.76(\mathrm{t}, 1 \mathrm{H}, J=7.2 \mathrm{~Hz}), 4.45(\mathrm{~d}$, $2 \mathrm{H}, J=6.0 \mathrm{~Hz}$ ), $3.12(\mathrm{br} \mathrm{s}, 4 \mathrm{H}), 2.88-2.51(\mathrm{~m}, 8 \mathrm{H}) ;{ }^{13} \mathrm{C}$ NMR $\left(101 \mathrm{MHz}, \mathrm{DMSO}-d_{6}\right): \delta 158.6,154.8,151.6,149.7,139.5,137.3,129.4$, $129.1,127.9,127.7,127.3,124.2,123.3,119.2,115.8,112.3,110.1,110.0,60.2,53.2,48.7,42.5,32.9 ;$ Anal. Calcd. for $\mathrm{C}_{28} \mathrm{H}_{29} \mathrm{~N}_{3} \mathrm{O}_{2}: \mathrm{C}_{\text {, }}$ $76.51 ; \mathrm{H}, 6.65 ; \mathrm{N}, 9.56$. Found: C, 76.48; H, 6.74; N, 9.47.

$\mathrm{N}$-(4-(2-(4-Phenylpiperazin-1-yl)ethyl)benzyl)benzo[b]thiophene-2-carboxamide dihydrochloride (19): White solid; Yield: 34\%; Mp 176-177 ${ }^{\circ} \mathrm{C}$ ( $\mathrm{HCl}$ salt); MS (ESI, $\left.m / z\right): 456.2[\mathrm{M}+1]^{+}$; ${ }^{1} \mathrm{H}$ NMR $\left(400 \mathrm{MHz}, \mathrm{DMSO}-d_{6}\right): \delta 11.51(\mathrm{~s}, 1 \mathrm{H}), 9.42(\mathrm{t}, 1 \mathrm{H}, J=6.0 \mathrm{~Hz}), 8.20(\mathrm{~s}$, $1 \mathrm{H}), 8.08-7.88(\mathrm{~m}, 2 \mathrm{H}), 7.51-7.38(\mathrm{~m}, 2 \mathrm{H}), 7.34(\mathrm{~d}, 2 \mathrm{H}, J=8.0 \mathrm{~Hz}), 7.30-7.20(\mathrm{~m}, 4 \mathrm{H}), 7.02(\mathrm{~d}, 2 \mathrm{H}, J=8.0 \mathrm{~Hz}), 6.87(\mathrm{t}, 1 \mathrm{H}, J=7.2$ $\mathrm{Hz}), 4.47(\mathrm{~d}, 2 \mathrm{H}, J=6.0 \mathrm{~Hz}), 3.82(\mathrm{~d}, 2 \mathrm{H}, J=10.8 \mathrm{~Hz}), 3.62(\mathrm{~d}, 2 \mathrm{H}, J=10.8 \mathrm{~Hz}), 3.41-3.05(\mathrm{~m}, 8 \mathrm{H}) ;{ }^{13} \mathrm{C} \mathrm{NMR}\left(101 \mathrm{MHz}, \mathrm{DMSO}-d_{6}\right)$ : $\delta 162.0,150.0,140.7,140.4,139.7,138.4,136.3,129.7,129.2,128.3,126.7,125.7,125.5,125.4,123.3,120.6,116.6,56.6,51.1,46.0$, 43.0, 40.7, 40.5, 40.3, 29.4; Anal. Calcd. for $\mathrm{C}_{28} \mathrm{H}_{29} \mathrm{~N}_{3} \mathrm{OS} .2 \mathrm{HCl}$ : C, 63.63; H, 5.91; N, 7.95. Found: C, 63.40; H, 6.06; N, 7.65.

$\mathrm{N}$-(4-(2-(4-Phenylpiperazin-1-yl)ethyl)benzyl)benzo[b]thiophene-3-carboxamide dihydrochloride (20): White solid; Yield: 27\%; Mp $179-180{ }^{\circ} \mathrm{C}(\mathrm{HCl}$ salt); MS (ESI, $m / z): 456.1[\mathrm{M}+1]^{+} ;{ }^{1} \mathrm{H}$ NMR $\left(400 \mathrm{MHz}, \mathrm{DMSO}-d_{6}\right): \delta 11.39(\mathrm{~s}, 1 \mathrm{H}), 9.08(\mathrm{t}, 1 \mathrm{H}, J=6.0 \mathrm{~Hz}), 8.53-$ $8.38(\mathrm{~m}, 2 \mathrm{H}), 8.04(\mathrm{~d}, 1 \mathrm{H}, J=7.7 \mathrm{~Hz}), 7.49-7.20(\mathrm{~m}, 8 \mathrm{H}), 7.01(\mathrm{~d}, 2 \mathrm{H}, J=8.0 \mathrm{~Hz}), 6.86(\mathrm{t}, 1 \mathrm{H}, J=7.2 \mathrm{~Hz}), 4.48(\mathrm{~d}, 2 \mathrm{H}, J=6.0 \mathrm{~Hz})$, $3.82(\mathrm{~d}, 2 \mathrm{H}, J=10.8 \mathrm{~Hz}), 3.62(\mathrm{~d}, 2 \mathrm{H}, J=10.8 \mathrm{~Hz}), 3.44-3.04(\mathrm{~m}, 8 \mathrm{H}) ;{ }^{13} \mathrm{C}$ NMR $\left(101 \mathrm{MHz}, \mathrm{DMSO}-d_{6}\right): \delta 162.6,149.0,138.9,137.8$, 136.8, 135.0, 130.3, 128.6, 128.1, 127.1, 124.3, 124.3, 124.0, 122.2, 119.5, 115.5, 55.6, 50.1, 44.9, 41.5, 39.7, 39.5, 39.3, 28.4; Anal. Calcd. for $\mathrm{C}_{28} \mathrm{H}_{29} \mathrm{~N}_{3} \mathrm{OS} .2 \mathrm{HCl}$ : C, 63.63; H, 5.91; N, 7.95. Found: C, 63.27; H, 6.00; N, 7.87.

\subsection{General procedure for the preparation of arylpiperazine derivative hydrochloride salts $\mathbf{2 1 - 2 3}$}

To a solution of $6(100 \mathrm{mg}, 3.39 \mathrm{mmol})$ in toluene $(20 \mathrm{~mL})$ was added the corresponding acid anhydride (1.5 equiv.). The reaction mixture was stirred at reflux for $16 \mathrm{~h}$. After cooling to ambient temperature, the reaction mixture was filtered through a Buchner funnel. After filtration the filtrate was concentrated in vacuo and the residue was purified by silica gel column chromatography using ethyl acetate/petroleum ether $(1 / 7, \mathrm{v} / \mathrm{v})$ as eluent to afford the corresponding products (21-23). To a solution of above corresponding products in ethyl acetate was added dropwise $4 \mathrm{~mol} / \mathrm{L} \mathrm{HCl}$ solution in ethyl acetate $(50 \mathrm{~mL})$, while maintaining stirring for $0.5 \mathrm{~h}$. Then the resulting solid was collected by filtration to give corresponding hydrochloride salts as a white solid.

2-(4-(2-(4-Phenylpiperazin-1-yl)ethyl)benzyl)-5-fluoroisoindoline-1,3-dione dihydrochloride (21) : White solid; Yield: 38\%; Mp 201-202 ${ }^{\circ} \mathrm{C}(\mathrm{HCl}$ salt); MS (ESI, $m / z): 444.1[\mathrm{M}+1]^{+} ;{ }^{1} \mathrm{H}$ NMR (400 MHz, DMSO- $\left.d_{6}\right): \delta 11.30(\mathrm{~s}, 1 \mathrm{H}), 7.96(\mathrm{dd}, 1 \mathrm{H}, J=8.2,4.5 \mathrm{~Hz})$, $7.78(\mathrm{dd}, 1 \mathrm{H}, J=7.4,2.2 \mathrm{~Hz}), 7.73-7.63(\mathrm{~m}, 1 \mathrm{H}), 7.29(\mathrm{~d}, 3 \mathrm{H}, J=8.3 \mathrm{~Hz}), 7.25(\mathrm{~d}, 3 \mathrm{H}, J=8.3 \mathrm{~Hz}), 7.01(\mathrm{~d}, 2 \mathrm{H}, J=8.0 \mathrm{~Hz}), 6.86(\mathrm{t}$, $1 \mathrm{H}, J=7.2 \mathrm{~Hz}), 4.75(\mathrm{~s}, 2 \mathrm{H}), 3.81(\mathrm{~d}, 2 \mathrm{H}, J=9.8 \mathrm{~Hz}), 3.61(\mathrm{~d}, 2 \mathrm{H}, J=9.8 \mathrm{~Hz}), 3.42-2.96(\mathrm{~m}, 8 \mathrm{H})$; Anal. Calcd. for $\mathrm{C}_{27} \mathrm{H}_{26} \mathrm{FN}_{3} \mathrm{O} .2 \mathrm{HCl}$ : C, 62.79; H, 5.46; N, 8.14. Found: C, 63.03; H, 5.59; N, 7.91.

2-(4-(2-(4-Phenylpiperazin-1-yl)ethyl)benzyl)-5-chloroisoindoline-1,3-dione dihydrochloride (22): White solid; Yield: 45\%; Mp 204-205 ${ }^{\circ} \mathrm{C}(\mathrm{HCl} \mathrm{salt})$; MS (ESI, $\left.m / z\right): 460.1[\mathrm{M}+1]^{+} ;{ }^{1} \mathrm{H}$ NMR $\left(400 \mathrm{MHz}, \mathrm{DMSO}-d_{6}\right): \delta 11.32(\mathrm{~s}, 1 \mathrm{H}), 7.90(\mathrm{dd}, 1 \mathrm{H}, J=8.0,4.6 \mathrm{~Hz})$, $7.80-7.65(\mathrm{~m}, 2 \mathrm{H}), 7.30(\mathrm{~d}, 3 \mathrm{H}, J=8.0 \mathrm{~Hz}), 7.26(\mathrm{~d}, 3 \mathrm{H}, J=8.0 \mathrm{~Hz}), 7.03(\mathrm{~d}, 2 \mathrm{H}, J=8.1 \mathrm{~Hz}), 6.78(\mathrm{t}, 1 \mathrm{H}, J=7.2 \mathrm{~Hz}), 4.76(\mathrm{~s}, 2 \mathrm{H})$, $3.82(\mathrm{~d}, 2 \mathrm{H}, J=9.8 \mathrm{~Hz}), 3.63(\mathrm{~d}, 2 \mathrm{H}, J=9.8 \mathrm{~Hz}), 3.46-2.94(\mathrm{~m}, 8 \mathrm{H})$; Anal. Calcd. for $\mathrm{C}_{27} \mathrm{H}_{26} \mathrm{ClN}_{3} \mathrm{O}_{2} .2 \mathrm{HCl}$ : C, 60.85; H, 5.30; N, 7.89. Found: C, 60.74; H, 5.38; N, 7.91 .

2-(4-(2-(4-Phenylpiperazin-1-yl)ethyl)benzyl)-5,6-dichloroisoindoline-1,3-dione (23): White solid; Yield: $40 \%$; Mp 103-104 ${ }^{\circ} \mathrm{C}$; MS (ESI, $m / z): 494.1[\mathrm{M}+1]^{+} ;{ }^{1} \mathrm{H}$ NMR $\left(400 \mathrm{MHz}, \mathrm{DMSO}-d_{6}\right): \delta 8.19(\mathrm{~s}, 2 \mathrm{H}), 7.42-7.09(\mathrm{~m}, 6 \mathrm{H}), 6.91(\mathrm{~d}, 2 \mathrm{H}, J=8.0 \mathrm{~Hz}), 6.76(\mathrm{t}, 1 \mathrm{H}$, $J=7.2 \mathrm{~Hz}), 4.73(\mathrm{~s}, 2 \mathrm{H}), 3.29$ (br s, 4H), 3.11 (br s, 4H), $2.74(\mathrm{t}, 2 \mathrm{H}, J=7.2 \mathrm{~Hz}), 2.56(\mathrm{t}, 2 \mathrm{H}, J=7.2 \mathrm{~Hz}) ;{ }^{13} \mathrm{C} \mathrm{NMR}(101 \mathrm{MHz}$ DMSO- $d_{6}$ ): $\delta 165.6,150.7,139.5,137.1,133.5,131.3,128.6,127.1,125.1,118.4,115.0,59.2,52.3,47.8$, 40.7, 32.0; Anal. Calcd. for $\mathrm{C}_{27} \mathrm{H}_{25} \mathrm{Cl}_{2} \mathrm{~N}_{3} \mathrm{O}_{2}$ : C, 65.59; H, 5.10; N, 8.50; Found: C, 65.45; H, 5.12; N, 8.46.

\subsection{Biological activity}

\subsubsection{Cell culture}

PC-3 and WPMY-1 cells were cultured in Dulbecco's modification Eagle's medium (DMEM, Invitrogen, Carlsbad, CA, USA) supplemented with $10 \%$ fetal bovine serum (FBS, Hyclone, Logan, UT, USA), $100 \mathrm{U} / \mathrm{mL}$ penicillin and $0.1 \mathrm{mg} / \mathrm{mL}$ streptomycin (Invitrogen). DU145 cells were cultured in RPMI1640 media supplemented with 10\% fetal bovine serum (FBS, Hyclone), $100 \mathrm{U} / \mathrm{mL}$ penicillin and $0.1 \mathrm{mg} / \mathrm{mL}$ streptomycin (Invitrogen). LNCaP cells were cultured in F12 media supplemented with $10 \%$ fetal bovine 
serum (FBS, Hyclone), $100 \mathrm{U} / \mathrm{mL}$ penicillin and $0.1 \mathrm{mg} / \mathrm{mL}$ streptomycin (Invitrogen). The cells were incubated at $37{ }^{\circ} \mathrm{C}$ in a humidified atmosphere with $5 \% \mathrm{CO}_{2}$.

\subsubsection{Assessment of antitumor activity by CCK-8 assay}

Cell proliferation was measured with the Cell Counting Kit-8 (CCK-8) assay kit (Dojindo Corp., Kumamoto, Japan). Cells were harvested during logarithmic growth phase and seeded in 96 -well plates at a density of $1 \times 10^{5}$ cells $/ \mathrm{mL}$, and cultured at $37{ }^{\circ} \mathrm{C}$ in a humidified incubator $\left(5 \% \mathrm{CO}_{2}\right)$ for $24 \mathrm{~h}$, followed by exposure to various concentrations of compounds tested for $24 \mathrm{~h}$. Subsequently $10 \mu \mathrm{L}$ of CCK-8 (Dojindo) was added to each well, the cells were then incubated for an additional $1 \mathrm{~h}$ at $37^{\circ} \mathrm{C}$ to convert WST-8 into formazan. Cell growth inhibition was determined by measuring the absorbance (Abs) at $\lambda=450 \mathrm{~nm}$ using a microplate reader. Three independent experiments were performed. Cell growth inhibition was calculated according to the following equation:

Growth inhibition $=(1-$ OD of treated cells/OD of control cells $) \times 100 \%$

The half maximal inhibitory concentrations $\left(\mathrm{IC}_{50}\right)$ were obtained from liner regression analysis of the concentration-response curves plotted for each tested compound.

\section{Results and discussion}

\subsection{Chemistry}

As depicted in Scheme 1, a series of novel arylpiperazine derivatives were synthesized starting from the commercially available 2(4-(bromomethyl)phenyl)acetic acid 1. First, compound $\mathbf{1}$ was reduced to alcohol $\mathbf{2}$ in the presence of a borane-methyl sulfide complex ( $2 \mathrm{~mol} / \mathrm{L}$ in tetrahydrofuran) at $0{ }^{\circ} \mathrm{C}$ for $1 \mathrm{~h}$, and then at room temperature for $10 \mathrm{~h}$. The intermediate 2 was directly used without further purification. The nucleophilic substitution reaction of compound $\mathbf{2}$ with phthalimide potassium salt in the presence of potassium carbonate $\left(\mathrm{K}_{2} \mathrm{CO}_{3}\right)$ gave compound 3 (70\% yield from compound 1) after $16 \mathrm{~h}$ at reflux. Compound 3 was treated with 4-toluenesulfonyl chloride in the presence of triethylamine and a catalytic amount of 4-dimethylaminopyridine at $0{ }^{\circ} \mathrm{C}$ for $16 \mathrm{~h}$ to generate compound 4 (95\% yield). The reaction of compound 4 with $\mathrm{N}$-Phenylpiperazine in the presence of $\mathrm{K}_{2} \mathrm{CO}_{3}$ at reflux for $16 \mathrm{~h}$ gave arylpiperazine derivative $\mathbf{5}$, and then the deprotection of the phthaloyl group gave amine compound $\mathbf{6}$. The intermediate $\mathbf{6}$ was directly used without further purification. Finally, the condensation of compound $\mathbf{6}$ and various acids (in the presence of DIPEA and HATU) or acid anhydrides gave arylpiperazine derivatives 7-23 (27-59\% yield; Scheme 1). The structures of the compounds (as their HCl salts) were confirmed using ${ }^{1} \mathrm{H}$ NMR, ${ }^{13} \mathrm{C} \mathrm{NMR}$, MS and elemental analyses $(\mathrm{C}, \mathrm{H}$, and $\mathrm{N})$.

\subsection{Evaluation of the bioactivity}

The synthesized target compounds 7-23 were evaluated for their in vitro cytotoxic activities against the three human prostate cancer cell lines (PC-3, LNCaP, and DU145), and compared with their effects on human prostate epithelial cell line WPMY-1 by CCK-8 assay[19-23]. The results are summarized in Table 1. As shown in Table 1, some compounds exhibited strong cytotoxic activities against the tested cancer cell lines, and even exhibited much better activity than naftopidil. For example, the compounds $\mathbf{8}, \mathbf{9}, \mathbf{1 0}, \mathbf{1 3}$, 16, 17, 18, 19, and 20 exhibited strong cytotoxic activities against the tested cancer cell lines $\left(\mathrm{IC}_{50}<10 \mu \mathrm{mol} / \mathrm{L}\right)$, and these compounds exhibited weak cytotoxic effects on human epithelial prostate normal cells WPMY-1. In addition, compounds $\mathbf{1 0}$ and 20 showed potent activity against tested cancer cells.

The SAR analysis revealed the following: (1) Compared to compound 7, compound $13\left(\mathrm{IC}_{50}=2.31\right.$ and $6.73 \mu$ mol/L, respectively) exhibited potent cytotoxic activities against LNCaP and DU145 cells. These results suggest that the introduction of a large hydrophobic group was beneficial for anti-cancer activity. Moreover, compound $\mathbf{1 3}$ exhibited weak cytotoxic effects on human epithelial prostate normal cells WPMY-1. (2) Compound 8 exhibited strong cytotoxic activities against PC-3 cells compared with compound 9, however, these activities decreased significantly in DU145 cells. (3) Compound $\mathbf{1 0}$ exhibited a more effective cytotoxic activity than compounds 11 and 12 against tested cancer cells. These results suggest that the introduction of a large group was beneficial for anti-cancer activity. In addition, compound 10 exhibited weak cytotoxic effects on human epithelial prostate normal cells WPMY-1. (4) Compound 14 lost potency $\left(\mathrm{IC}_{50}>50 \mu \mathrm{mol} / \mathrm{L}\right)$ against LNCaP and DU145 cells compared with compound 13 . These results suggest that the introduction of $\beta$-naphtholyl group was detrimental for anti-cancer activity. (5) Moreover, compounds containing $\alpha$-indolyl group showed better activity for PC-3 cells than did the $\alpha$-naphtholyl group for PC-3 cells, as exemplified by compound 16 ( $\left.\mathrm{IC}_{50}=5.50 \mu \mathrm{mol} / \mathrm{L}\right)$ which showed strong activity, while compound 13 lost potency $\left(\mathrm{IC}_{50}>50 \mu \mathrm{mol} / \mathrm{L}\right)$. (6) Compounds 16, 18, and 19 containing heteroatom at the aryl group displayed potent cytotoxic activity against DU145 cells $\left(\mathrm{IC}_{50}=5.50,5.17\right.$ and $8.21 \mu$ mol/L, respectively). Moreover, these compounds exhibited weak cytotoxic effects on human epithelial prostate normal cells WPMY-1. In addition, compounds $\mathbf{1 8}$ and 19 showed excellent selective activity for DU145 cells over the other tested cancer cells. (7) Compared to compound 19, compound 20 $\left(\mathrm{IC}_{50}=5.30,3.29\right.$ and $1.23 \mu \mathrm{mol} / \mathrm{L}$, respectively) exhibited strong cytotoxic activities against PC-3, LNCaP and DU145 cells. These results suggest that the introduction of a 3-benzo[b]thiophenyl group was beneficial for anti-cancer activity. (8) To compare the cytotoxic activities of arylpiperazine amide derivatives 7-23 against PC-3, LNCaP and DU145 cells, arylpiperazine imide derivatives 21, 22, and 23 (Scheme 1) were synthesized. As shown in Table 1, compounds 21, 22 and 23 exhibited weak to moderate cytotoxic activities against the tested cancer cell lines, however, the intermediate $\mathbf{5}\left(\mathrm{IC}_{50}=2.23 \mu \mathrm{mol} / \mathrm{L}\right)$ exhibited strong cytotoxic activities against DU145 cells.

\section{Conclusion}


This paper has reported the synthesis and biological evaluation against three human prostate cancer cells and human prostate epithelial cells of a novel class of arylpiperazine derivatives. Some compounds exhibited strong cytotoxic activities against tested cancer cell lines. Compounds 8, 10 and 20 demonstrated a relatively strong cytotoxicity against PC-3 and DU145 cells $\left(\mathrm{IC}_{50}<2\right.$ $\mu \mathrm{mol} / \mathrm{L}$ ). These positive results could serve as a valuable guideline for further research on arylpiperazine derivatives as novel antiprostate cancer agents. Further research involving other classes of arylpiperazine derivatives is in progress.

\section{Acknowledgment}

The project was supported by the Technological Innovation Project of Colleges and Universities in Guangdong Province (No. cx2d1127), the China Postdoctoral Science Foundation (Nos. 2013M542165, 2013M531837), the National Science Foundation of Guangdong Province (No. S2013040014088) and the Guangzhou Postdoctoral Scientific Research Foundation (Nos. Q130, Q074).

\section{References}

[1] R.T. Greenlee, M.B. Hill-Harmon, T. Murray, M. Thun, Cancer statistics, 2001, CA: Cancer J. Clin. 51 (2001) 15-36.

[2] M. Quinn, P. Babb, Patterns and trends in prostate cancer incidence, survival, prevalence and mortality. Part I: international comparisons, BJU Int. 90 (2002) 162-173.

[3] H. Grönberg, Prostate cancer epidemiology, Lancet 361 (2003) 859-864.

[4] J.T. Isaacs, Role of androgens in prostatic cancer, Vitam. Horm. 49 (1994) 433-502.

[5] A. Beedassy, G. Cardi, Chemotherapy in advanced prostate cancer, Semin. Oncol. 26 (1999) 428-438.

[6] C. Falciani, J. Brunetti, C. Pagliuca, et al., Design and in vitro evaluation of branched peptide conjugates: Turning nonspecific cytotoxic drugs into tumorselective agents, ChemMedChem 5 (2010) 567-574.

[7] I. Tannock, Cell kinetics and chemotherapy: a critical review, Cancer Treat. Rep. 62 (1978) 1117-1133.

[8] K. Vinaya, C.V. Kavitha, S. Chandrappa, et al., Synthesis and antileukemic activity of novel 4-(3-(piperidin-4-yl) propyl) piperidine derivatives, Chem. Biol. Drug Des. 78 (2011) 622-630.

[9] F. Berardi, C. Abate, S. Ferorelli, et al., Novel 4-(4-aryl)cyclohexyl-1-(2-pyridyl) piperazines as $\Delta_{8}-\Delta_{7}$ sterol isomerase (emopamil binding protein) selective ligands with antiproliferative activity, J. Med. Chem. 51 (2008) 7523-7531.

[10] C. Abate, M. Niso, M. Contino, et al., 1-Cyclohexyl-4-(4-arylcyclohexyl) piperazines: mixed $\sigma$ and human $\Delta_{8}-\Delta_{7}$ sterol isomerase ligands with antiproliferative and p-glycoprotein inhibitory activity, ChemMedChem 6 (2011) 73-80.

[11] W.H. Liu, J.X. Chang, Y. Liu, J.W. Luo, J.W. Zhang, Design, synthesis and activities of novel benzothiazole derivatives containing arylpiperazine, Acta Pharmaceut. Sinica 48 (2013) 1259-1265.

[12] M. Dellabella, G. Milanese, G. Muzzonigro, Efficacy of tamsulosin in the medical management of juxtavesical ureteral stones, J. Urol. 170 (2003) 22022205.

[13] T. Morita, I. Wada, H. Saeki, S. Tsuchida, R.M. Weiss, Ureteral urine transport: changes in bolus volume, peristaltic frequency, intraluminal pressure and volume of flow resulting from autonomic drugs, J. Urol. 137 (1987) 132-135.

[14] Y. Nishino, T. Masue, K. Miwa, et al., Comparison of two $\alpha_{1}$-adrenoceptor antagonists, naftopidil and tamsulosin hydrochloride, in the treatment of lower urinary tract symptoms with benign prostatic hyperplasia: a randomized crossover study, BJU Int. 97 (2006) 747-751.

[15] Y. Kojima, S. Sasaki, Y. Kubota, et al., Expression of $\alpha_{1}$-adrenoceptor subtype mRNA as a predictor of the efficacy of subtype selective $\alpha_{1}$-adrenoceptor antagonists in the management of benign prostatic hyperplasia, J. Urol. 179 (2008) 1040-1046.

[16] Y. Hori, K. Ishii, H. Kanda, et al., Naftopidil, a selective $\alpha_{1}$-adrenoceptor antagonist, suppresses human prostate tumor growth by altering interactions between tumor cells and stroma, Cancer Prev. Res. 4 (2011) 87-96.

[17] H. Kanda, K. Ishii, Y. Ogura, et al., Naftopidil, a selective $\alpha-1$ adrenoceptor antagonist, inhibits growth of human prostate cancer cells by G1 cell cycle arrest, Int. J. Cancer 122 (2008) 444-451.

[18] E. Masachika, T. Kanno, T. Nakano, A. Gotoh, T. Nishizaki, Naftopidil induces apoptosis in malignant mesothelioma cell lines independently of $\alpha_{1}-$ adrenoceptor blocking, Anticancer Res. 33 (2013) 887-894.

[19] H. Chen, X. Liang, F. Xu, et al., Synthesis and cytotoxic activity evaluation of novel arylpiperazine derivatives on human prostate cancer cell lines, Molecules 19 (2014) 12048-12064.

[20] H. Chen, F. Xu, X. Liang, et al., Design, synthesis and biological evaluation of novel arylpiperazine derivatives on human prostate cancer cell lines, Bioorg. Med. Chem. Lett. 25 (2015) 285-287.

[21] G.J.L. Kaspers, A.J. Veerman, R. Pieters, et al., In vitro cellular drug resistance and prognosis in newly diagnosed childhood acute lymphoblastic leukemia, Blood 90 (1997) 2723-2729.

[22] G.J.L. Kaspers, R. Pieters, C.H. Van Zantwijk, et al., Prednisolone resistance in childhood acute lymphoblastic leukemia: vitro-vivo correlations and crossresistance to other drugs, Blood 92 (1998) 259-266.

[23] J. Ding, S.L. Huang, S.Q. Wu, et al., Gain of miR-151 on chromosome 8q24.3 facilitates tumour cell migration and spreading through downregulating RhoGDIA, Nat. Cell Biol. 12 (2010) 390-399. 

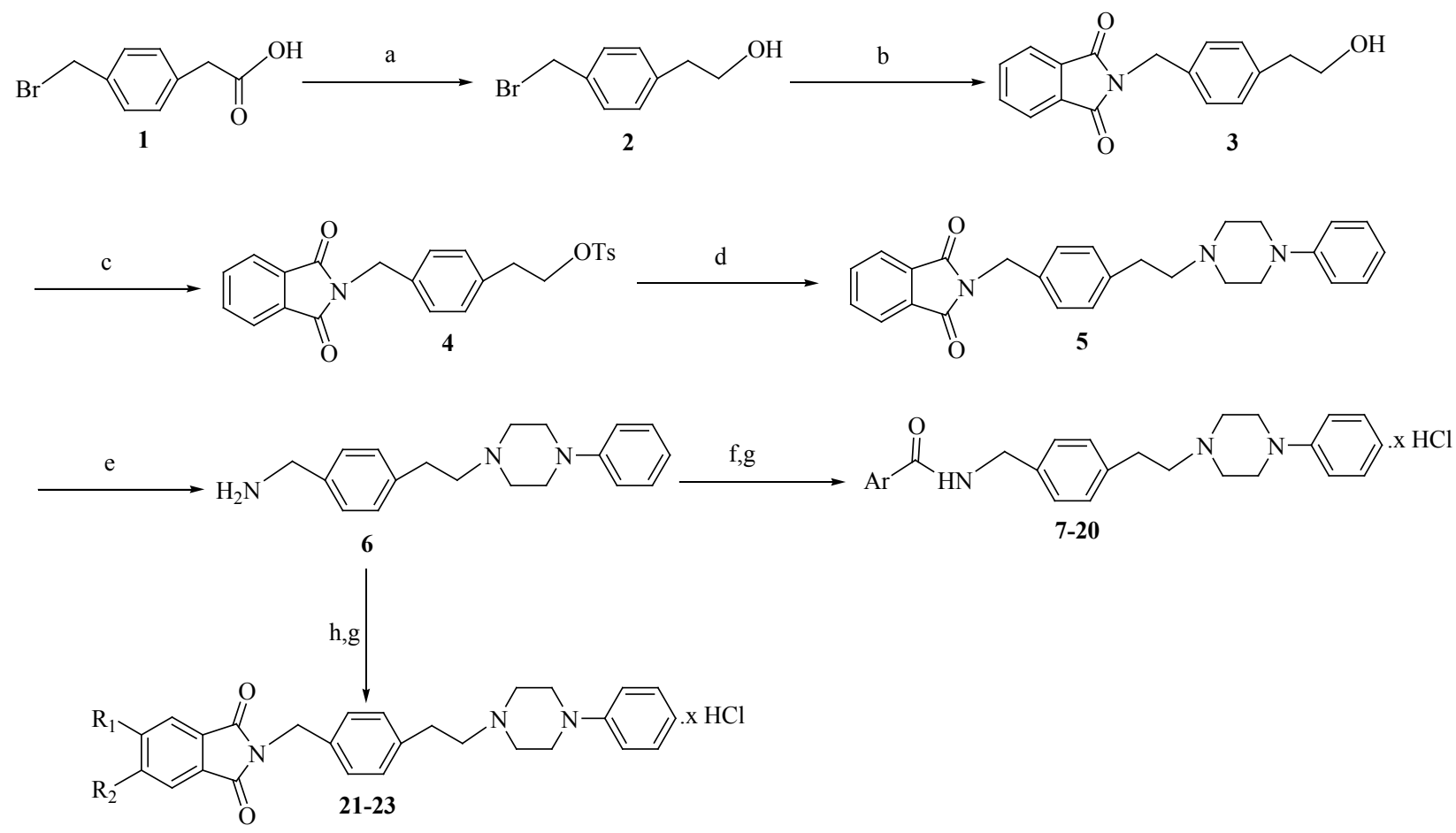
7, $\mathrm{Ar}=-1$
8, $\mathrm{Ar}=$
9, $\mathrm{Ar}=-1$
10, $\mathrm{Ar}=\frac{1}{\mathrm{Z}} \longrightarrow$
$11, \mathrm{Ar}=\frac{1}{1}$
12, $\mathrm{Ar}=-1<$
13 ,<smiles>[Te]=CC=[Al]I</smiles><smiles>Fc1ccc2[nH]c(I)cc2c1</smiles><smiles>C[Al](C)([AlH2])[AlH2]</smiles>
14, $\mathrm{Ar}=$
15, $\mathrm{Ar}=$<smiles>CC(C)(C)c1ccc(F)c2ccccc12</smiles><smiles></smiles>
16, $\mathrm{Ar}=1$
21, $\mathrm{R}_{1}=\mathrm{F}, \mathrm{R}_{2}=\mathrm{H}$
22, $\mathrm{R}_{1}=\mathrm{Cl}, \mathrm{R}_{2}=\mathrm{H}$
23, $\mathrm{R}_{1}=\mathrm{Cl}, \mathrm{R}_{2}=\mathrm{Cl}$

Scheme 1. Synthetic route of compounds 7-23. Reagents and conditions: (a) $\mathrm{BH}_{3} . \mathrm{S}\left(\mathrm{CH}_{3}\right)_{2}$, THF, $0{ }^{\circ} \mathrm{C}$ for $1 \mathrm{~h}$, and then room temperature for $10 \mathrm{~h}$; (b)

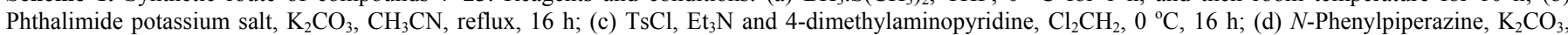
$\mathrm{CH}_{3} \mathrm{CN}$, reflux, $16 \mathrm{~h}$; (e) $\mathrm{N}_{2} \mathrm{H}_{4} \cdot \mathrm{H}_{2} \mathrm{O}$, EtOH, room temperature, 16 h; (f) Acids, DIPEA, HATU, $\mathrm{Cl}_{2} \mathrm{CH}_{2}$, room temperature, 16 h; (g) $\mathrm{HCl}$, AcOEt, room temperature, $0.5 \mathrm{~h}$; (h) Acid anhydrides, toluene, reflux, $16 \mathrm{~h}$. 
Table 1 In vitro cytotoxicity of compounds 7-23

\begin{tabular}{|c|c|c|c|c|}
\hline \multirow[t]{2}{*}{ Compd. } & \multicolumn{3}{|c|}{$\mathrm{IC}_{50}(\mu \mathrm{mol} / \mathrm{L})^{\mathrm{a}}$} & \multirow[b]{2}{*}{$\mathrm{WPMY}^{\mathrm{b}}{ }^{\mathrm{b}}$} \\
\hline & PC- $3^{\mathrm{b}}$ & $\mathrm{LNCaP}^{\mathrm{b}}$ & DU145 ${ }^{\mathrm{b}}$ & \\
\hline 5 & $>50$ & $>50$ & $2.23 \pm 0.29$ & $>50$ \\
\hline 7 & $33.42 \pm 0.67$ & $>50$ & $13.26 \pm 0.48$ & $>50$ \\
\hline 8 & $1.05 \pm 0.27$ & $>50$ & $>50$ & $43.06 \pm 0.39$ \\
\hline 9 & $>50$ & $13.44 \pm 0.54$ & $4.06 \pm 0.07$ & $>50$ \\
\hline 10 & $1.18 \pm 0.08$ & $6.23 \pm 0.24$ & $1.23 \pm 0.09$ & $>50$ \\
\hline 11 & $47.69 \pm 1.67$ & $33.21 \pm 0.68$ & $44.62 \pm 1.02$ & $>50$ \\
\hline 12 & $32.60 \pm 0.14$ & $25.26 \pm 0.60$ & $26.06 \pm 1.13$ & $>50$ \\
\hline 13 & $>50$ & $2.31 \pm 0.05$ & $6.73 \pm 0.30$ & $>50$ \\
\hline 14 & $>50$ & $>50$ & $>50$ & $>50$ \\
\hline 15 & $>50$ & $33.30 \pm 0.49$ & $>50$ & $>50$ \\
\hline 16 & $5.50 \pm 0.34$ & $>50$ & $5.50 \pm 0.32$ & $>50$ \\
\hline 17 & $>50$ & $29.57 \pm 0.43$ & $2.42 \pm 0.30$ & $>50$ \\
\hline 18 & $27.60 \pm 0.04$ & $17.79 \pm 0.20$ & $5.17 \pm 0.17$ & $>50$ \\
\hline 19 & $>50$ & $14.30 \pm 0.56$ & $8.21 \pm 0.60$ & $40.12 \pm 1.40$ \\
\hline 20 & $5.30 \pm 0.14$ & $3.29 \pm 0.09$ & $1.23 \pm 0.08$ & $>50$ \\
\hline 21 & $>50$ & $>50$ & $>50$ & $>50$ \\
\hline 22 & $>50$ & $32.16 \pm 1.62$ & $22.17 \pm 1.25$ & $>50$ \\
\hline 23 & $>50$ & $>50$ & $47.70 \pm 1.14$ & $>50$ \\
\hline naftopidil & $42.10 \pm 0.79$ & $22.36 \pm 0.61$ & $34.58 \pm 0.31$ & $>50$ \\
\hline
\end{tabular}

${ }^{\mathrm{a}} \mathrm{IC}_{50}$ values are taken as means \pm standard deviation from three experiments.

${ }^{\mathrm{b}} \mathrm{PC}-3, \mathrm{LNCaP}$ and DU145, human prostate cancer cell line; WPMY-1, the human prostate epithelial cell line. 


\section{Graphical Abstract}

Design, synthesis and biological evaluation of novel arylpiperazine derivatives on human prostate cancer cell lines

Hong Chen ${ }^{\mathrm{a}, \mathrm{b}, 1}$, Fang Xu ${ }^{\mathrm{b}, 1}$, Bing-Bing Xu ${ }^{\mathrm{b}, 1}$, Jing-Yi Xu ${ }^{\mathrm{b}}$, Bin-Hao Shao ${ }^{\mathrm{b}}$, Bi-Yun Huang ${ }^{\mathrm{b}}$, Mu Yuan ${ }^{\mathrm{b}, *}$

${ }^{a}$ College of Chemistry and Chemical Engineering, Luoyang Normal University, Luoyang 471022, China

${ }^{\mathrm{b}}$ Pharmaceutical Research Center, Guangzhou Medical University, Guangzhou 510182, China

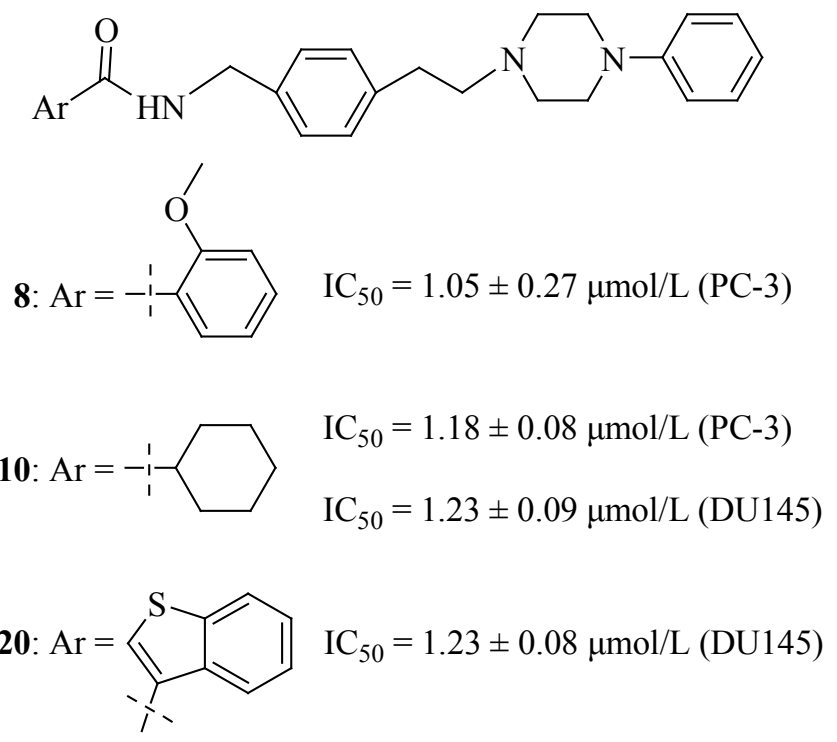

A novel series of arylpiperazine derivatives was synthesized and evaluated for their cytotoxic activity against three human prostate cancer cell lines. Among all, compounds 8, 10 and $\mathbf{2 0}$ exhibited strong cytotoxic activities against the tested cancer cells. 